\title{
A importância da motivação dos estudantes e o uso de técnicas de engajamento para apoiar a escolha de jogos no ensino de programação
}

\author{
Tatyane S. C. da Silva ${ }^{1}$, Patricia C. de A. R. Tedesco ${ }^{1}$, Jeane C. B. de Melo ${ }^{2}$ \\ ${ }^{1}$ Universidade Federal de Pernambuco (UFPE)
}

Av. Prof. Moraes Rego, 1235 - Cidade Universitária - CEP: 50670-901 - Recife - PE - Brasil

${ }^{2}$ Universidade Federal Rural de Pernambuco (UFRPE)

Rua D. Manoel de Medeiros, s/n, Dois Irmãos - CEP: 52171-900 - Recife - PE - Brasil

\{taty.calixto, jeane.ufrpe\}@gmail.com, pcart@cin.ufpe.br

\begin{abstract}
Programming courses typically have high failure rates, which cause discouragement and student dropout in Computing courses. Thus, the motivational aspect can assist students to continue working even when facing difficulties. From this perspective, games possess in their development elements that guarantee the existence of motivation. Given this scenario, this paper aims to propose guidelines to assist teachers in choosing games for teaching programming based on students engagement techniques and player profiles.
\end{abstract}

Resumo. A disciplina de programação apresenta elevados índices de reprovação causando desmotivação e desistência dos alunos no curso de Computação. Sendo assim, o aspecto motivacional pode auxiliar os estudantes a prosseguirem frente às dificuldades. Nessa perspectiva, os games possuem em seu desenvolvimento elementos que garantem a existências da motivação. Diante desse cenário, este artigo objetiva propor diretrizes para auxiliar os docentes na escolha adequada de jogos para o ensino de programação baseada nas técnicas de engajamento e perfis de jogadores.

\section{Introdução}

O aprendizado de programação apresenta muitos desafios devido à sua inerente complexidade, onde os estudantes precisam desenvolver a competência de solucionar problemas algoritmicamente. Tais dificuldades são a grande causa de reprovação, desmotivação e desistência dos estudantes nos cursos de Computação (Santos et al. 2009).

Segundo Ryan e Deci (2000), a motivação intrínseca representa uma tendência natural para buscar novos desafios, obter e exercitar as próprias capacidades. Refere-se ao envolvimento em determinada atividade por sua própria causa, por esta ser interessante, envolvente ou de alguma forma, geradora de satisfação. Nessa perspectiva, surgem os jogos, que podem ser idealizados com o intuito de incluir elementos que possam despertar, estimular, ou mesmo, explorar a motivação intrínseca (Sena e Coelho 2012). 
O que favorece a utilização de jogos no ensino é o fato de que, geralmente, os jovens apresentam uma grande motivação no ato de jogar. Segundo Prensky (2012), essa combinação é chamada de "Aprendizagem baseada em Jogos Digitais", cuja sigla em inglês é DGBL - Digital Game-Based Learning.

Diante deste panorama, o presente trabalho tem por objetivo propor diretrizes que auxiliem os professores a escolher adequadamente os games para o ensino de programação, considerando a motivação intrínseca do discente, o uso de técnicas de engajamento e estilos de jogos para aprendizagem que sejam adequados aos tipos de jogadores. Este artigo está organizado da seguinte forma: na Seção 2 são abordadas a motivação dos jogadores e as técnicas de engajamento. A aprendizagem baseada em jogos digitais é apresentada na Seção 3. A proposta das diretrizes é tratada na Seção 4. Na Seção 5 são feitas as considerações finais bem como a proposta de trabalhos futuros.

\section{A motivação dos jogadores e as técnicas de engajamento}

Ghozland (2010) afirma que a importância da experiência de um jogo depende da quantidade de motivação que ele pode gerar. Segundo Bartle (1996) há jogadores com perfis diferentes e suas respectivas formas de serem motivados através dos jogos. Esse autor publicou um estudo onde propõe uma taxonomia para entender como os diversos perfis de jogadores são motivados e os classificou em quatro categorias: realizadores, exploradores, socializadores e predadores.

Os realizadores são motivados através do cumprimento das missões e orgulham-se de sua posição na hierarquia do jogo. Os jogadores classificados exploradores gostam de interagir com o mundo virtual do jogo e de serem surpreendidos pelo mesmo (Bartle 1996).

Os socializadores, por sua vez, gostam de relacionar-se com outros jogadores e orgulham-se de sua influência. A quarta e última categoria, os predadores, têm o interesse de mostrar o quanto são superiores a outros jogadores, que são vistos como seus inimigos (Bartle 1996).

As técnicas de engajamento são definidas como procedimentos de game design usados para motivar e manter o jogador interessado no game (Sena e Coelho 2012). A seguir são apresentadas algumas técnicas de engajamento:

i. Desafios e Missões: O sentimento de realização de uma missão ou desafio tem um grande efeito na motivação do jogador;

ii. Achievements ou Badges: são prêmios dados aos jogadores após obtenção de uma conquista ou realização de uma tarefa;

iii. Progress Bar: tem como objetivo mostrar a evolução do jogador ao longo do jogo;

iv. Rankings e Leader Board: aumenta a motivação dos jogadores através da competição entre eles. 
Com base nas técnicas de engajamento apresentadas, a tabela 1 relaciona a melhor escolha de técnicas de engajamento, tendo em vista o perfil do jogador, segundo Sena e Coelho (2012).

Tabela 1 - Relação entre técnicas de engajamento, subjetividade e perfil dos jogadores

\begin{tabular}{|c|c|}
\hline Técnicas de engajamento & Perfil do Jogador \\
\hline Achievements ou Badges. & $\begin{array}{c}\text { Realizadores, Socializadores } \mathrm{e} \\
\text { Exploradores. }\end{array}$ \\
\hline Desafios e Missões. & Realizadores e Exploradores. \\
\hline Rankings e Leader Boards. & Predadores e Socializadores. \\
\hline Progress Bar. & Todos. \\
\hline
\end{tabular}

\section{Aprendizagem baseada em jogos digitais}

De modo geral, há grande motivação dos jovens no ato de jogar, contrastando com o desinteresse que estes demonstram pelos conteúdos curriculares. Essa atitude dos estudantes é um reflexo do interesse crescente pelo aprendizado informal adquirido pela internet, construído de forma autônoma, baseado em seus próprios interesses. Nessa perspectiva, o ambiente de jogos pode ser classificado como informal, visto que estes propiciam um ambiente multissensorial e de intenso envolvimento para os jogadores, favorecendo, portanto, o interesse na utilização de jogos como meio de ensino para essa nova geração (Prensky 2012).

Apresentamos na tabela 2, algumas definições dos estilos de jogos para aprendizagem e suas características (Prensky 2012):

Tabela 2 - Estilos de jogos para aprendizagem

\begin{tabular}{|c|c|c|}
\hline Estilo de jogos & Características & Exemplo \\
\hline $\begin{array}{l}\text { Jogos } \\
\text { intrínsecos. }\end{array}$ & $\begin{array}{l}\text { O Conteúdo é a parte integrante da } \\
\text { estrutura do jogo. }\end{array}$ & $\begin{array}{l}\text { A maioria de jogos de Simulação. Por } \\
\text { exemplo, um game de simulação de } \\
\text { voo, em que o próprio jogo trata de } \\
\text { pilotar um avião. }\end{array}$ \\
\hline $\begin{array}{l}\text { Jogos } \quad \text { de } \\
\text { reflexão. }\end{array}$ & $\begin{array}{l}\text { Jogos que oferecem pausas } \\
\text { embutidas para reflexão. }\end{array}$ & $\begin{array}{l}\text { Jogos de RPG, aventura, simulação e } \\
\text { estratégia. }\end{array}$ \\
\hline Jogos de Ação. & $\begin{array}{l}\text { Jogos que oferecem menos } \\
\text { oportunidades de reflexão. }\end{array}$ & Jogos de luta, jogos de tiro. \\
\hline
\end{tabular}




\section{Proposta de diretrizes}

As diretrizes propostas na atual sessão têm como objetivo auxiliar os docentes na escolha adequada de jogos para o ensino de programação, com o intuito de motivar os alunos durante o processo de aprendizagem desta disciplina. Para esse fim, uma relação entre os estilos de jogos para aprendizagem, o perfil do jogador e técnicas de engajamento se faz necessária, podendo guiar a utilização de games no ensino de programação.

A primeira relação ocorre entre as técnicas de engajamento: Achievements ou Badges, com o perfil dos jogadores realizadores e exploradores e os estilos de jogos intrínsecos. Os games que simulem as estruturas básicas (variáveis, constantes), estruturas de controle (if, else, switch,for, while) e funções ou métodos são exemplos de jogos com estilo intrínsecos que podem ser utilizados para o ensino de programação.

A segunda relação acontece entre desafios e missões com jogadores realizadores e exploradores, presentes em jogos de reflexão. Para o ensino de programação os jogos de RPG podem ser utilizados como uma alternativa para a resolução dos problemas. Ao utilizar os jogos de RPG os problemas transformam-se em missões e desafios que precisam ser superados para avançar no game e ganhar pontos. Além disso, o jogo RPG deve apresentar uma narrativa envolvente para que os alunos possam se sentir motivados a cumprir as missões e desafios.

Os predadores se interessam por games de combate e por isso jogos de ação são adequados para eles. A utilização de leader boards e ranking promove a motivação dos jogadores propagando a reputação dos jogadores no ambiente. Para o ensino de programação pode-se usar as estruturas de controle (if, else, switch,for,while), funções ou métodos substituindo o uso dos controles do teclado em jogos de ação.

Todos os jogos e perfis de jogador se adaptam a técnica de engajamento de progress bar. Uma vez que, a técnica auxilia os jogadores, a saber, sua evolução no jogo em relação ao objetivo final.

A tabela 3, a seguir, apresenta um resumo da proposta apresentada nesta sessão, que indica o uso de técnicas de engajamento, tendo em vista o perfil do jogador e estilos de jogos para aprendizagem.

Tabela 3 - Resumo da relação entre: técnicas de engajamento, o perfil do jogador e estilos de jogos de aprendizagem

\begin{tabular}{|c|c|c|}
\hline Técnicas de engajamento & Perfil do Jogador & Estilo de Jogos \\
\hline Achievements ou Badges. & $\begin{array}{c}\text { Realizadores e } \\
\text { Exploradores. }\end{array}$ & Jogos intrínsecos. \\
\hline Desafios e Missões. & $\begin{array}{l}\text { Realizadores e } \\
\text { Exploradores. }\end{array}$ & Jogos de reflexão. \\
\hline
\end{tabular}


III Congresso Brasileiro de Informática na Educação (CBIE 2014)

XXV Simpósio Brasileiro de Informática na Educação (SBIE 2014)

\begin{tabular}{|c|c|c|}
\hline Leader Boards e Ranking. & Predadores. & Jogos de ação. \\
\hline Progress Bar. & Todos os perfis. & Todos os Jogos. \\
\hline
\end{tabular}

\section{Considerações finais e trabalhos futuros}

Diante das dificuldades apresentadas pelos estudantes na disciplina de programação, é importante destacar o aspecto motivacional no seu aprendizado. Embora a motivação intrínseca seja importante no processo de aprendizagem de programação, e esteja presente no ambiente de jogos, é preciso que haja uma manutenção da motivação. Para que isso ocorra podem-se utilizar técnicas de engajamento para garantir a permanência do jogador no game.

Assim, este trabalho propôs diretrizes para auxiliar o professor na escolha de jogos adequados para o ensino de programação, com o objetivo de motivar o estudante, através da relação entre os estilos de games para aprendizagem, técnicas de engajamento e o perfil do jogador.

Uma proposta de trabalho futuro é identificar os perfis dos jogadores usando o teste de Bartle, que apresenta uma série de perguntas e uma pontuação que acompanha a forma de classificação de jogadores (Wei 2009) e mapear games para ensino de programação que se adequem aos perfis dos jogadores e que contemplem as diretrizes propostas neste artigo e aplicálos em turmas inicias em cursos de Ciência da Computação e analisar se há melhora na motivação dos estudantes e na aprendizagem.

\section{Referências}

Bartle, R. (1996). "Heart, Clubs, Diamond, Spades: players who suit muds". The Journal of Virtual Environments, 1(1). Disponível em: http://www.mud.co.uk/richard/hcds.htm.

Ghozland, D. (2010). "Designing for Motivation. Gamasutra". Disponível em: http://www.gamasutra.com/view/feature/1419/designing_for_motivation.php.

Prensky,M.(2012).Aprendizagem Baseada em Jogos Digitais, São Paulo, Editora Senac, $1^{\mathrm{a}}$ edição.

Ryan,R.M., Deci,E.L.(2000).Intrinsic and Extrinsic Motivations: Classic Definitions and New Directions. Contemporary Educational Psychology 25, 54-67.

Santos, J. G.; Fechine, J.; Costa, E.(2009). “Analogus: Um Ambiente para Auxílio ao Ensino de Programação Orientado pelo Raciocínio por Analogia”. XXII SBIE - XVII WEI.

Sena,A. e Coelho,D.K (2012). "Motivação dos Jogadores de Videogame - Uma breve visão sobre as Técnicas de Engajamento". XI SBGAMES.

Wei,Q. Gamers and the Games They Play. Monografia (Bachelor of Science): Faculty of Worcester Polytechnic Institute, Worcester, Estados Unidos.2009. 